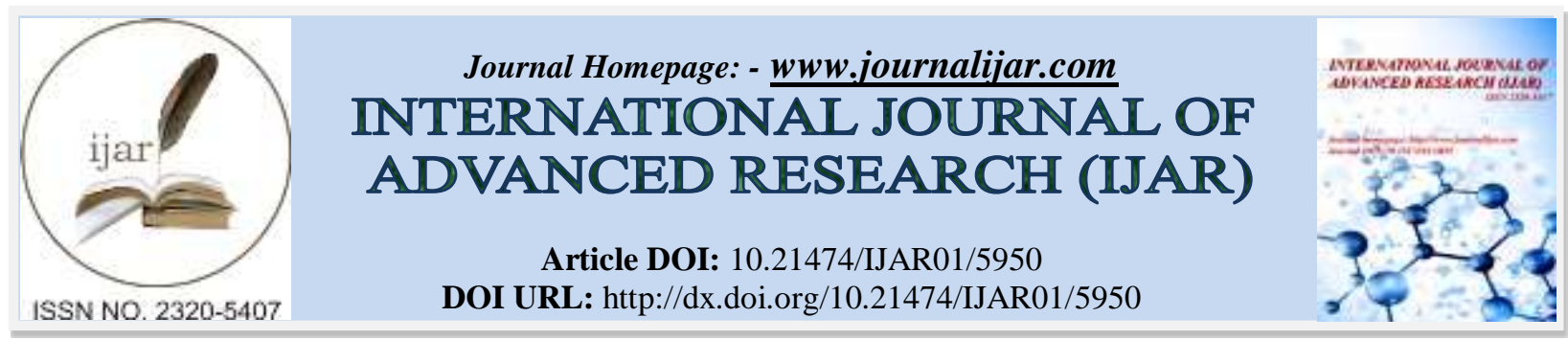

RESEARCH ARTICLE

\title{
TOXIC EFFECTS ON BIOCHEMICAL AND HEMATOLOGICAL PARAMETERS IN RATS EXPOSED TO JUDO 40.
}

Inoka Kudavidanage ${ }^{1}$ and "L. Dinithi C. Peiris".

1. Department of Department of Natural Resources, Sabaragamuwa University, Belihuloya, Sri Lanka.

2. Department of Zoology (Center for Biotechnology), University of Sri Jayewardenepura.

\section{Manuscript Info}

Manuscript History

Received: 02 October 2017

Final Accepted: 04 November 2017

Published: December 2017

Key words:-

Judo 40, hematological parameters,

ALT, AST and ALP

\begin{abstract}
The present study investigated the hematological, and biochemical, changes due to Judo 40 toxicity in male Wistar albino rats. Two sets of male rats ( $\mathrm{n}=9 /$ group) were orally treated with $20 \mathrm{mg} / \mathrm{kg}$ and $50 \mathrm{mg} / \mathrm{kg}$ of Judo 40 or the vehicle (corn oil) in four fractions for two consecutive days. The first of animals were autopsied on day 1 to assess the liver toxicity while the second set of animals were autopsied on posttreatment day 3 to assess hematological parameters. Both doses of Judo 40 intoxication induced a significant increase in PCV, and WBCs count. Moreover, there was a significant increase in serum biochemical parameters related to hepatic injury: alanine aminotransferase (ALT), aspartate aminotransferase (AST), alkaline phosphatase (ALP). In general, it was concluded that, Judo 40 could induce hepatotoxicity and alter PCV and WBC counts indicating exposure to Judo 40 could pose risk to human health.
\end{abstract}

Copy Right, IJAR, 2017, All rights reserved.

\section{Introduction:-}

Pesticides are used extensively in large amounts causing environmental damage (Sharma et al. 2005). Several studies have shown that increase usage of man-made chemicals result in destructive reproductive function in animals (Peiris et al. 1995 and Peiris-John \& Wickremasinghe, 2008) and in humans (Skakkebaek et al., 2006, Dhanushka \& Peiris, 2017). Organophosphate (OP) pesticides exert their toxic effects mainly by inhibiting phosphorylate of acetylcholinesterase enzyme, causing accumulation of acetylcholine in synapses (Colovic et al. 2013). Many studies have identified association between expose to OP and reproductive disorders such as infertility, birth defect, adverse pregnancy outcomes and perinatal deaths (Peiris and Moore 2001a, Peiris and Moore 2001b, Ratnasooriya et al. 1996, Dayananda \& Peiris, 2016a, Dayananda \& Peiris, 2016b).

Judo 40, an organophosphorous pesticide is the commercial formulation of Chlorpyrifos (O, O-diethyl O-3, 5, 6trichloro-2-pyridil) phosphorothioate that is marketed as an emusifiable concentrate containing $400 \mathrm{~g} / \mathrm{L}$ of active ingredient. Judo 40 is widely used in Sri Lanka because of its wide spectrum insecticide property. The toxic mechanism of Judo 40 is by its active ingredient chlorpyrifos, which metabolize to chlorpyrifos-oxon and 3,5,6trichloro-2-pyridinol. Judo 40 is highly toxic to targeted organisms. Chlorpyrifos (CPF) has anticholinesterase activity in animal tissues and is highly toxic to many animals including copepods, fish (Brandit et al. 2015), rats (Peiris and Dhanushka, 2017) and mammals (Deb and Das, 2013). Further it is known that Judo 40 can reduce functional parameters and induce DNA damages in human spermatozoa (Kudavidanage and Peiris, 2016). These

Corresponding Author: - L. Dinithi C. Peiris.

Address: - Department of Zoology (Center for Biotechnology), University of Sri Jayewardenepura. 
insecticides can reach water bodies by surface runoff on cultivated lands. Thus it is vital to consider toxic effects to biota.

In tihs context, biomarkers are important tools to understand how organisms respond to a given toxic insult in both natural and laboratory conditions. At present, several enzymes related to biotransformation and detoxification of xenobiotics, are currently used in ecotoxicological research. Activities of catalase, gluthathione-S-transferase (Di Giulio and Hinton, 2008); biotranformation enzymes are either increased or inhibited under conditions of chemical stress, while hepatic alanine aminotransferase (ALT) and aspartate aminotransferase (AST), are indicators of liver damages (van der Oost et al., 2003). Both enzymes are found in great amounts in hepatocytes, and when hepatic damages occur, enzymes can leakage in to the plasma, which could be measured to determine such damages (Giannini, 2005). It is well documented that pesticides are of the environmental pollutants that cause damage in the circulatory system and all blood components (Chatterjee et al., 2013). Hematological techniques are the most common method to determine sub-lethal effects of pollutants (Larsson et al., 1985). Hence, the present study aimed to determine the effects of judo 40 on haematological and biochemical parameters of male rats following chronic exposure.

\section{Materials and Methods:-}

Test material:-

Test material, Judo 40 (commercial product of chlorpyrifos; concentration 400g/L) was obtained from Lankem Ceylon Ltd., Colombo 10. Since Judo 40 is soluble in corn oil, was used as the control.

\section{Experimental design:-}

Previously, we found that $20 \mathrm{mg} / \mathrm{kg}$ and $50 \mathrm{mg} / \mathrm{kg}$ doses (calculated for active ingredient) was detrimental for human spermatozoa and hence same douses were used for the present study (Kudavidanage and Peiris, 2016). Twenty seven male rats were randomly divided in to 3 groups $(\mathrm{n}=9)$. Rats in groups 1 and $2 \mathrm{received} 20 \mathrm{mg} / \mathrm{kg}$ and $50 \mathrm{mg} / \mathrm{kg}$ Judo 40 and the rats in the control group received corn oil only. The doses were administered twice a day between $8.00 \mathrm{am}-9.00$ am and $15.00 \mathrm{pm}-16.00 \mathrm{pm}$ for 2 alternative days. All dosing experiments were replicated. Different sets of animals were used for hematological and liver toxicity assessments.

\section{Toxicological observations:-}

The first set of animals were observed daily between 11.00 a.m. and 12 noon for any overt signs of toxicity (diarrhea, salivation, lachrymation, tremors, ataxia, loss of fur, change of fur color, postural abnormalities or behavioral changes), stress (fur erection and exophthalmia), aversive behaviors, during the treatment period.

\section{Liver toxicity:-}

The second set of animals were autopsied on post treatment day 1 to assess the liver toxicity. Blood collected from heart puncture was allowed to clot for 25-30 $\mathrm{min}$ at room temperature $\left(28-30^{\circ} \mathrm{C}\right)$ and centrifuged at $3000 \mathrm{rpm}$ for 10 min to separate serum. Serum samples were analyzed for alanine aminotransferase (ALT) and aspartate aminotransferase (AST) and alkaline phosphate (ALP) activities using enzyme test kit (Biolab Reagent, France). Absorption was measured using a spectrophotometer (Labomed, INC. Los Angeles, USA) at 340 nm wavelength.

\section{Hematological Studies:-}

The first set of animals was used for the hematological study. Animals were autopsied on post-treatment day 3 and blood was collected from heart puncture. Immediately after collecting blood from the cardiac puncture, about one ml of blood was added in to micro tubes containing EDTA. Subsequently, blood parameters; red blood cell count (RBC), total and differential leukocyte count, hematocrit (HCT). total hemoglobin (Hb) and WBC differential counts were determined.

\section{Statistical analysis:-}

Statistical analysis was performed with Two-way analysis of variance (ANOVA) using Minitab software package (Minitab Co., USA) for the main effect of pesticides. Where a significant treatment effect was found, differences among individual group means were tested by "Tukey 95\%". The data are expressed as mean \pm SD. The statistical difference was determined at $P<0.05$. 


\section{Results:- \\ Behavioral toxicity:-}

Acute poisoning symptoms such as salivation, difficulty to breathing, convulsion, rigid posture, piloerection, and reddening around the mouth and the nose were observed. Symptoms started appearing with the second faction of dosing and climaxed with the last fraction of the dosing. Symptoms subsidized on the first day post-treatment and fully disappeared with the second day post-treatment. Diarrhea was observed in all three groups, most serenely with the high dose.

\section{Blood parameters:-}

There was no significant difference between red blood cell counts were observed between the two treatments and the control. Significant $(\mathrm{p}<0.05)$ increase in the WBC count was seen at both treated groups when compared to the control. Similarly, packed cell volume for $20 \mathrm{mg} / \mathrm{kg}$ dose and $50 \mathrm{mg} / \mathrm{kg}$ dose were $22.56 \%$ and $26.58 \%$ respectively. These values significantly differ from the control $(\mathrm{p}<0.01)$ indicating Judo 40 affects PCV in a dose related manner (Table 1).

Table 1 summarizes the results of the WBC differential cell count. No impairment was evident for any of the counts at both dose levels.

\section{Liver toxicity measurements:-}

Treatment of $50 \mathrm{mg} / \mathrm{kg}$ body weight of Judo 40 significantly $(\mathrm{p}<0.01)$ increased the serum ALT, ASP and ALP levels at both dose levels (Table 2).

\section{Discussion:-}

Pesticide exposure pose a major health hazard, specially, chronic exposure might lead alteration in the biochemical parameters thus leading to various adverse conditions. Hence in the present the effect of Judo 40 on hematological parameters and liver enzymes following 30-day exposure. The present study revealed elevations in the values of WBC and PCV levels at both dose levels. Increased in PCV is often associated with an elevation of RBC and WBC counts (Mairbauri, 2013). In the present study increased WBC levels were observed at both dose levels, thus leading to reduction in PCV. Furthermore, PCV can also be a consequence of decreased plasma volume, which could occur as a result of diarrhea and/or dehydration (Mellgren, 2011). Since both dehydration though reduced water intake and diarrhea were observed in the treated animals leading to observed increased PCV levels.

Hepatic dysfunction may occur due to ingestion or inhalation of hepatotoxicity (Bhattacharya et al., 2008). Present study exhibited increased levels of ALT, AST and ALP. Similar results were observed for chlorphyrifos, the metabolic product of Judo 40 (Peiris \& Dhanushka, 2017). Similar to AST and ALT, ALP is also a component in hepatocytes, mucosal epithelia of small intestine, proximal tubule of kidney, bone, and placenta and help in lipid transportation in the intestine. The serum ALP activity is mainly from the liver and therefore, elevated levels of ALP could indicate liver damage (Munro et al., 2006). Due to liver injury disturbances in the transport function of the hepatocytes could result, which in turn could give rise to leakage of enzyme due to altered permeability of plasma membranes leading to increase enzyme levels in the plasma (Giannini, 2005). Further, activity increased in the liver has been related to compensatory mechanisms of tissue damage, or due to protein catabolism that occur when animals are under stress (David et al., 2004). An activity decreased of enzymes in the liver has been related to cytolysis processes and the consequent release of them into the blood stream (Bacchetta et al., 2011; Bhattacharya et al., 2008). It had been shown that toxic effects due pesticides exposure can be reversed by treating with herbal formulations (Peiris et al., 2015). Finally, it can be concluded that exposure of rats to functions were decreased with exposure of Judo 40 could result in increase PCV, WBC parameters and liver damage. Therefore, exposure to Judo 40 could pose a risk to human health.

Table I: - Effects of Judo 40 hematological parameters

\begin{tabular}{|c|c|c|c|}
\hline \multirow[t]{2}{*}{ Parameters } & \multirow[t]{2}{*}{ Control (Corn oil) } & \multicolumn{2}{|c|}{ Treatment (Judo 40) } \\
\hline & & $20 \mathrm{mg} / \mathrm{kg}$ & $50 \mathrm{mg} / \mathrm{kg}$ \\
\hline \multicolumn{4}{|c|}{ Blood parameters } \\
\hline $\operatorname{RBC}\left(10^{6} / \mathrm{ml}\right)$ & $7.54+0.526$ & $6.94 \pm 0.38$ & $7.09 \pm 0.54$ \\
\hline $\mathrm{WBC}\left(10^{3} / \mathrm{ml}\right)$ & $11.42 \pm 0.74$ & $16.49 \pm 0.97 *$ & $16.1 \pm 1.10^{*}$ \\
\hline PCV & $19.9+0.51$ & $22.56 \pm 0.76 * *$ & $26.58 \pm 0.67 * *$ \\
\hline
\end{tabular}




\begin{tabular}{|l|l|l|l|}
\hline Hb content (g/l) & $14.13 \pm 0.29$ & $13.62 \pm 0.59$ & $14.4 \pm 0.43$ \\
\hline WBC differential counts & $29.9 \pm 3.1$ & $25.5 \pm 2.1$ & $27.2+3.6$ \\
\hline Neutrophils (\%) & $8.7 \pm 1.2$ & $12.4+2.4$ & $10.4+1.6$ \\
\hline Eosinophils (\%) & $2.9 \pm 0.7$ & $4.1+0.4$ & $5.0+0.2$ \\
\hline Basophils (\%) & $52.0 \pm 4.1$ & $49.4+6.3$ & $50.8+4.3$ \\
\hline Lymphocytes (\%) & $6.4 \pm 2.2$ & $7.7+2.4$ & $5.1+1.8$ \\
\hline Monocytes (\%) & $6.15 \pm 0.085$ & $5.89+0.048^{* * *}$ & $5.85+0.045^{* * *}$ \\
\hline pH of seminal vesicle fluid & &
\end{tabular}

The data are given as mean \pm SEM $(n=9)$. Values are statistically significant at $* \mathrm{p}<0.05, * * \mathrm{p}<0.01$. Control group was given Corn oil while treated group was given $20 \mathrm{mg} / \mathrm{kg} \& 50 \mathrm{mg} . \mathrm{kg}$ chlorpyrifos.

Table 2:- Serum levels of serum ALT, AST and ALP in animals treated with $20 \mathrm{mg} / \mathrm{kg}, 50 \mathrm{mg} / \mathrm{kg}$ (T2) Judo 40 and the control (corn oil)

\begin{tabular}{|l|l|l|l|}
\hline Serum parameters & Control & $\mathbf{2 0 ~} \mathbf{~ m g} / \mathbf{k g}$ & $\mathbf{5 0} \mathbf{~ m g} / \mathbf{k g}$ \\
\hline Hepatotoxicity & $19.53 \pm 2.64$ & $34.20 \pm 2.20^{* *}$ & $39.20 \pm 2.20^{* *}$ \\
\hline ALT (U/L) & $18.86 \pm 4.13$ & $52.69 \pm 6.69^{* *}$ & $71.69 \pm 6.69^{* * *}$ \\
\hline AST (U/L) & $700.34 \pm 11.54$ & $1200.63 \pm 10.74^{*}$ & $1500.63 \pm 10.74^{* *}$ \\
\hline ALP (U/L)
\end{tabular}

ALT: alanine aminotransferase; AST: aspartate aminotransferase and ALP: alkaline phosphate. The data are given as mean $\pm \operatorname{SEM}(\mathrm{n}=9)$. Values are statistically significant at $* \mathrm{P}<0.05, * * \mathrm{P}<0.01, * * * \mathrm{P}<0.001$

\section{References:-}

1. Bacchetta C., Cazenave J., Parma M.J. \& Biancucci, G.F. (2011). Biochemical stress responses in tissues of the cichlid fish Cichlasoma dimerus exposed to a com- mercial formulation of endosulfan. Archives of Envrionmental Contamination 61: 453-460,

2. Bhattacharya H., Xiao Q. \& Lun L. (2008). Toxicity studies of nonylphenol on rosy barb (Puntius conchonious): a biochemical and histopathological evaluation. Tissue Cell 40: 243-249.

3. Brandt, C., Burnett, D.C., Arcinas, L., Palace, V., Anderson, W., G. (2015). Effects of chlorpyrifos on in vitro sex steroid production and thyroid follicular development in adult and larval lake Sturgeon Acipenser fulvescens. Chmosphere, 132:179-197

4. Colovic M.B., Krstic, D. Z., Lazarevic-Past, T.D., Bondzic, A.M., Vasic, V.M. (2013). Acetylcholine esterase inhibitors: Pharmacology and Toxicology. Current Neruopharmacol, 11 (3): 315-335.

5. David M., Mushigeri S.B., Shivakumar R. \& Philip G.H. (2004). Response of Cyprinus carpio (Linn) to sublethal concentration of cypermethrin: alterations in protein metabolic profiles. Chemosphere 56 (4): $347-$ 352.

6. Dayananda P.V. \& Peiris L Dinithi C (2016 a). Morphological and functional alterations of human spermatozoa after incubation with two organophosphorus insecticides. Wulfenia Journal. 23(10):1-9.

7. Dyananda P.V. \& Peiris L. Dinithi C (2016 b). Toxic effects of Tebufenozide on human sperm in vitro. International Journal of Advanced Scientific Research. 5(6): 61-72.

8. Deb N. \& Das S. (2013) Chlorpyrifos toxicity in fish: A review. Current World Environment Journal 8: 174184.

9. Dhanushka M.A.T. \& Peiris L.D.C. (2017). Cytotoxic and Genotoxic Effects of Acephate on Human Sperm. Journal of Toxicology, vol. 2017, Article ID 3874817, 6 pages, 2017. doi:10.1155/2017/3874817.

10. Di Giulio R.T. \& Hinton, D.E. (2008). The Toxicology of Fishes. CRC Press, New York.

11. Giannini E.G., Testa R. \& Savarino V. (2005). Liver enzyme alteration: a guide for clinicians. Canadian Medical Association Journal 172(3):367-37

12. Mairbäurl H. (2013). Red blood cells in sports: effects of exercise and training on oxygen supply by red blood cells. Frontiers in Physiology. 4: 332.

13. Mauro P., Renze B. \& Wouter W. (2006). Enzymes. In: Tietz text book of clinical chemistry and molecular diagnostics. 4th edition. Carl AB, Edward R, David EB, editors. Elsevier pp. 604-616.

14. Mellgren E. (2011). Glycerol to diary calves - effects on intestinal health and fluid balance. M.Sc. Thesis, Swedish University of Agricultural Science, Uppsala, Sweden.

15. Peiris D.C. \& Dhanushka T (2017). Low doses of chlorpyrifos interfere with spermatogenesis of rats through reduction of sex hormones. Environmental Science and Pollution Research. 24(26):20859-20867. 
16. Peiris D.C., Jayatilleka H. \& Dhanushka T (2015). Evaluation of aqueous leaf extract of Cardiospermum halicacabum (L.) on fertility of male rats. Biomed Central International Research 2015; Article ID: 175726,

17. Peiris L.D.C., Jayathunga YNA, Ratnasooriya W.D. (1995). Antirepro-ductive effects in male rats exposed to methamidophos. Ceylong Journal of Science; 24: 53-9.

18. Peiris L.D.C. \& Moore H.D.M. (2001a). Effects of acute and chronic doses of methoxy acetic acid on hamster sperm fertilizing ability. Asian Journal of Andrology 3: 209-216.

19. Peiris L.D.C. \& Moore H.D.M. (2001b). Effects of acute and chronic doses of methoxy acetic acid on hamster sperm fertilizing ability

20. Peiris-John R.J. \& Wickremasinghe R. (2008) Impact of low-level exposure to organophosphates on human reproduction and survival. Transaction of the Royal Society of Tropical Medicine and Hygiene 102: 239-245.

21. Ratnasooriya W.D., Jayatunga Y.N.A. \& Peiris L.D.C. (1996). Monocrotophos impairs the fertility of male rats. Medical Science Research 24: 403406.

22. Skakkebaek N E. Jørgensen N. Main K M. Rajpert-De Meyts E. Leffers H. \& Andersson A M. et al (2006). Is human fecundity declining? International Journal of Andrology 29: 2-11.

23. van der Oost R., Beyer J. \& Vermeulen, N.P.E. (2003). Fish bioaccumulation and biomarkers in environmental risk assessment: a review. Environ. Toxicology \& Pharmacology 13: 57-149. 